\title{
Management of an old woman with cavernous sinus thrombosis with two different mechanisms: case report and review of the literature
}

\author{
Traian Flavius Dan ${ }^{1-3)}$, Silviana Nina Jianu4), Nicoleta IaCoB ${ }^{5)}$, ANDRei GheORGHe Marius Motoc ${ }^{2,6)}$,

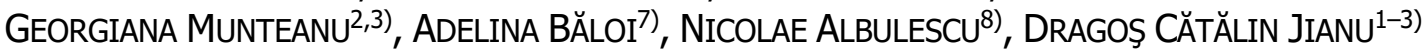 \\ 1) Department of Neurology, Victor Babeş University of Medicine and Pharmacy, Timişoara, Romania \\ ${ }^{2)}$ Centre for Cognitive Research in Neuropsychiatric Pathology (NeuroPsy-Cog), Victor Babeş University of Medicine \\ and Pharmacy, Timişoara, Romania \\ 3) First Department of Neurology, Pius Brânzeu Emergency County Hospital, Timişoara, Romania \\ 4) Department of Ophthalmology, Dr. Victor Popescu Military Emergency Hospital, Timişoara, Romania \\ 5) Department of Multidetector Computed Tomography and Magnetic Resonance Imaging, Neuromed Diagnostic Imaging \\ Centre, Timişoara, Romania \\ 6) Department of Anatomy and Embryology, Victor Babeş University of Medicine and Pharmacy, Timişoara, Romania \\ 7) Department of Anesthesia and Intensive Care, Pius Brânzeu Emergency County Hospital, Timişoara, Romania \\ 8) Department of Cardiology, Pius Brânzeu Emergency County Hospital, Timişoara, Romania
}

\begin{abstract}
Cavernous sinus thrombosis (CST) usually produces a characteristic clinical syndrome. Septic CST represents a sporadic, but severe complication of infection of the cavernous sinuses, which can bring high mortality and morbidity rates if not treated right away. Case presentation: The current research is a case report of a 64-year-old woman with inherited thrombophilia who developed an acute mastoid infection that resulted in septic right CST. The clinical diagnosis was verified by laboratory studies and evidence from high-resolution computed tomography (HRCT), magnetic resonance imaging (MRI), and magnetic resonance angiography (MRA). Clinical medical care resulted in the patient being successfully treated with low-molecular-weight heparin and broad-spectrum intravenous antibiotics, which avoided severe complications.
\end{abstract}

Keywords: cavernous sinus thrombosis, mastoid infection, inherited thrombophilia, low-molecular weight heparin.

\section{a Introduction}

Cavernous sinus thrombosis (CST) represents the single cerebral veins and sinus thrombosis which produces a characteristic clinical syndrome. CST usually has an infectious cause. Septic CST is an uncommon but lifethreatening complication of cavernous sinus infection. It was linked to high mortality rates in the pre-antibiotic period [1]. The outcome of this condition has improved considerably since the advent and widespread use of antibiotics, but it still depends on prompt diagnosis and treatment. Potential treatment modalities include antibiotics, anticoagulation, and corticosteroids, together with surgical treatment for source control infection [2].

On the one hand, the main cause of CST can be a distant focus, with septicemia that can lead up to thrombosis of the cavernous sinus. On the other hand, infection might spread from the facial regions, via the facial venous vessels and the ophthalmic veins or from the sphenoid sinus, straight to the adjacent cavernous sinus [3]. Among the most common causes that favor this condition, we mention nasal furuncle, which is presumed to be the commonest cause of CST $(50 \%)$, accompanied by ethmoidal or sphenoidal sinuses $(30 \%)$ and dental infections $(10 \%)[4,5]$.
Tonsils, soft palate, middle ear, mastoid, and orbit are some of the less frequent main infection areas. The highly anastomotic venous system of the paranasal sinuses enables infection to spread retrogradely to the cavernous sinus through the superior and inferior ophthalmic veins $[6,7]$.

When dealing with these patients, a variety of factors must be considered. This involves the cause of the infection, the causative organism(s) and therefore the best antibiotics choice, the existence of any underlying medical condition(s), and surgical care, if necessary.

\section{Aim}

We discuss the case of a patient with CST who presented a favorable outcome. The main purpose of our paper is to report the clinical and neuroimaging features, the treatment and outcome of our patient, and compare them with those outlined in literature.

\section{ㅁ Case presentation}

A 64-year-old female arrived at our Hospital's Emergency Department with a one-day history of severe headache and right periorbital and mid-facial swelling. Two weeks earlier, the patient experienced fever $\left(39^{\circ} \mathrm{C}\right)$,

This is an open-access article distributed under the terms of a Creative Commons Attribution-NonCommercial-ShareAlike 4.0 International Public License, which permits unrestricted use, adaptation, distribution and reproduction in any medium, non-commercially, provided the new creations are licensed under identical terms as the original work and the original work is properly cited. 
headache, light pain in the right ear, purulent secretion from the ear (otorrhea), swelling and redness of the skin behind the right ear, tinnitus, and hearing disorder, which drived her to seek treatment from a general practitioner (GP) in a rural health clinic. She was sent to the nearest Ear-Nose-Throat (ENT) Service. A native head computed tomography (CT) was performed (Figure 1) and was diagnosed with right acute mastoiditis. She was treated with antibiotics [Amoxicillin $500 \mathrm{mg}$ three times a day (ter die sumendum - TDS)], painkillers and anti-inflammatory drugs for several days. Initially, her symptoms have improved slightly, but severe headache, anorexia, and high fever appeared after a few days, followed by confusion.

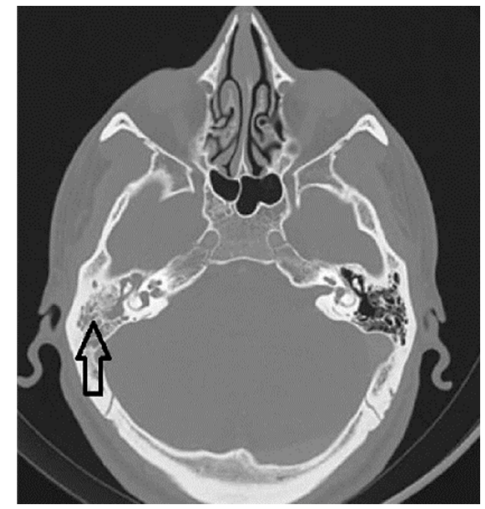

Figure 1 - Axial HRCT images of both temporal bones. Right mastoiditis with partial sclerosis of mastoid air cells (arrow). Contralateral normal ear is presented for comparison. HRCT: Hight-resolution computed tomography.

She presented a medical history of arterial hypertension for which she received treatment with angiotensinconverting enzyme (ACE) inhibitors.

On ophthalmological examination, we observed marked right facial and periorbital swelling, associated with righ blepharoptosis, chemosis, and proptosis. She had a visual acuity of $7 / 12$ on her right eye. There were no visual fields abnormalities. The intraocular pressures in both eyes were normal, there was no relative afferent pupillary defect, and color vision was normal. On both sides, fundoscopy revealed no signs of optic disc swelling. The left eye seemed to be fine.

On neuro-ophthalmological examination, she displayed a wide spectrum of eye movements, but complained of

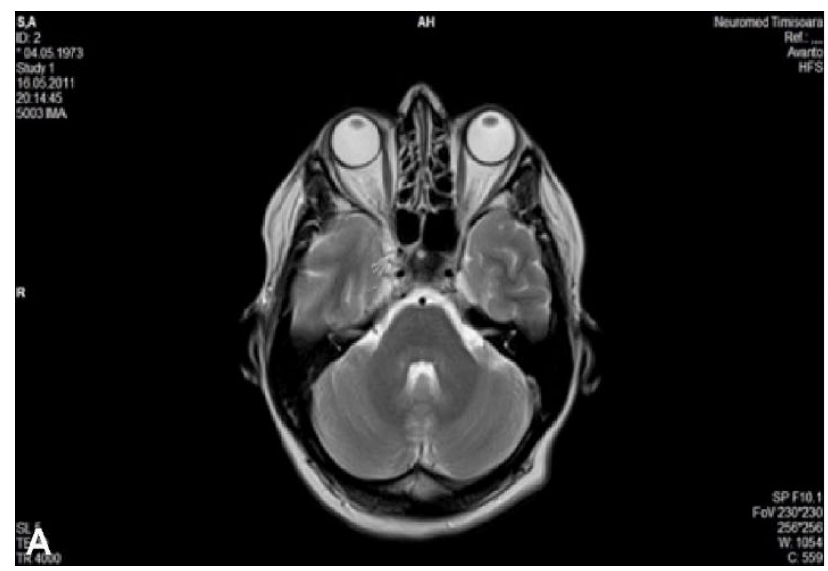

pain on right eye movement. There was no clinical evidence of right optic nerve compression. No trigeminal sensory deficit was present. She was febrile $\left(38.8^{\circ} \mathrm{C}\right)$, conscious, but somnolent, and there were no other neurological deficits.

Her cardiovascular and respiratory examination were both normal.

At presentation, blood cultures were taken. Her inflammatory parameters were significantly elevated (white blood cells count $18 \times 10^{4} / \mathrm{L}$, erythrocyte sedimentation rate $67 \mathrm{~mm} / \mathrm{h}$, C-reactive protein $250 \mathrm{mg} / \mathrm{L}$ ), with renal and liver functions within normal limits. While tests for vasculitis, human immunodeficiency virus (HIV), and diabetes were all negative, we discovered a prothrombin G20210A mutation (PT20210A).

Her coagulation profile and urinalysis were both normal.

Magnetic resonance imaging (MRI) of the brain revealed non-opacification of the right cavernous sinus (Figure 2, A and B; Figure 3).

As blood cultures were being obtained, she received empirically high-dose intravenous (iv) Ceftriaxone $[2 \mathrm{~g}$ twice a day (bis in die - BD)] and anticoagulation with Enoxaparin (8000 IU BD). She did not received corticosteroids. After two days, we had the results of blood cultures, which were positive for Streptococcus pneumoniae, so we continued the prior antibiotic treatment, as the antibiogram showed that it was sensible to Ceftriaxone.

Four days after admission, she developed shortness of breath, and reduced oxygen saturation. A chest X-ray revealed unilateral homogeneous opacification on right lobar lung with air bronchograms specific to a right lobar pneumonia. At this stage, she was referred to the Intensive Care Unit (ICU) and needed non-invasive mechanical ventilation. Her antibiotics were changed to Amikacin $20 \mathrm{mg} / \mathrm{kg}$ once a day (omne in die - OD) + PiperacillinTazobactam $4.5 \mathrm{~g}$ TDS because of a suspicion of a hospital acquired pneumonia, which was confirmed by the chest X-ray and bronchial aspirate culture and the antibiotics were adapt to the antibiogram. Following this, she began to improve, and her symptoms resolved in the coming days. She was transferred back to our Service after seven days.

A control contrast-enhanced magnetic resonance angiography (CE-MRA) was performed, which shows the persistence of the lacunar image in the right cavernous sinus (Figures 4 and 5).

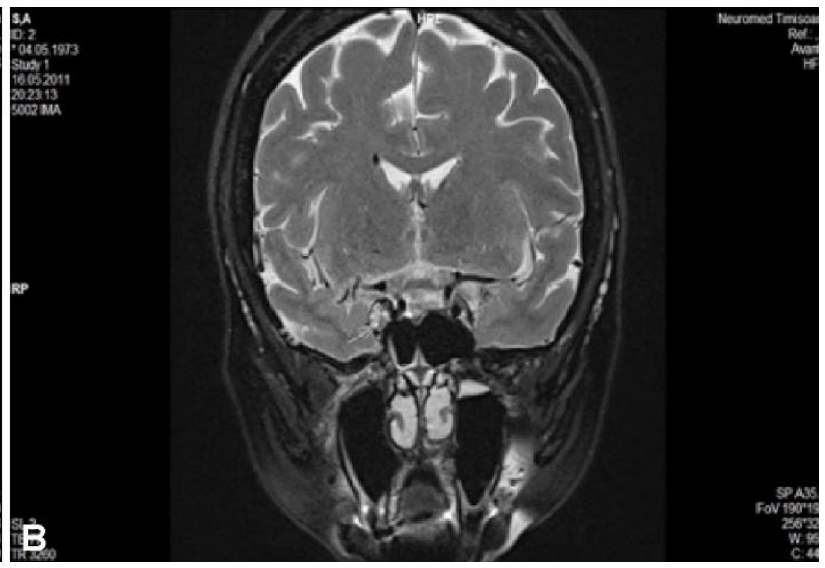

Figure 2 - MRI showing asymmetry of the cavernous sinuses with the enlargement of the right cavernous sinus as it has a modified signal in native sequence: (A) Axial; (B) Coronal (mixed signal T2 TSE-acute/subacute thrombus) and postcontrast with non-gadolinium uptake - with the aspect of lacunar image. MRI: Magnetic resonance imaging; TSE: Turbo spin echo. 


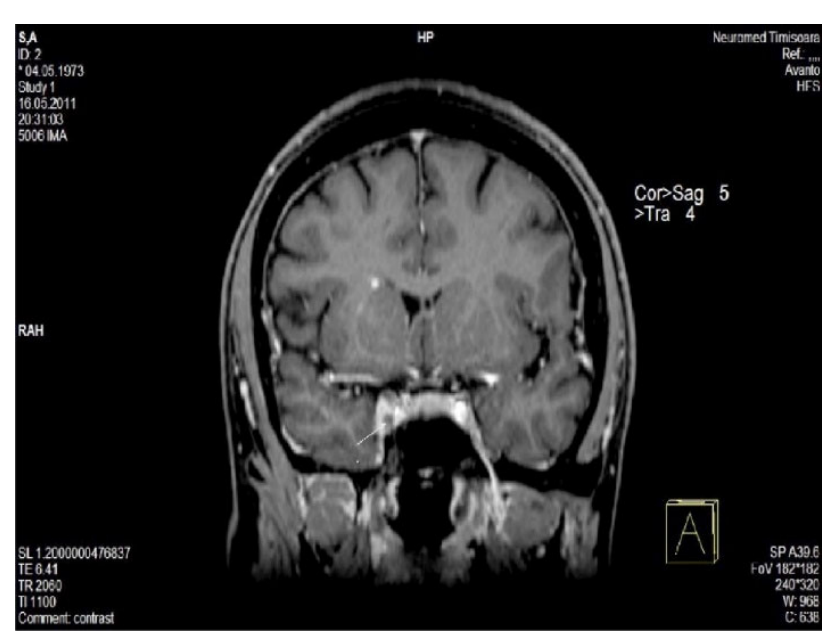

Figure 3 - MRI, T1 post-contrast reconstruction in coronal plane: remaining lacunar image in right cavernous sinus in late time post-contrast administration accompanied with thickening of the nearby meninges. MRI: Magnetic resonance imaging.

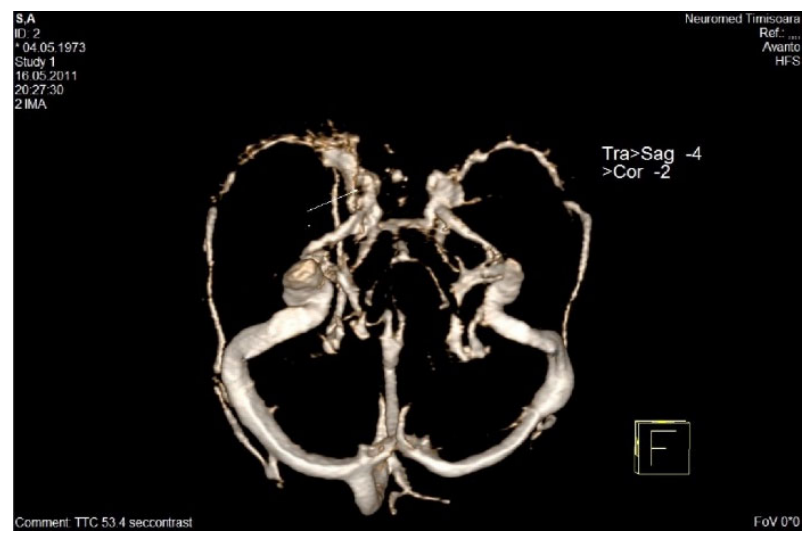

Figure 5-CE-MRA, venous time - VRT reconstruction in axial plane: lacunar image in right cavernous sinus (arrow). CE-MRA: Contrast enhanced-magnetic resonance angiography; VRT: Volume rendering technique.

Her ophthalmological symptoms improved with the above-mentioned treatment and the peri-orbital swelling has diminished. She was discharged two weeks later, on oral anticoagulant - Acenocoumarol, and if a follow-up CT venogram will indicate resolution of the thromboses after three months, the treatment will be stopped. She ultimately made a full recovery.

\section{口 Discussions}

As it was mentioned before in many studies, CST usually has an infectious cause. It represents the single cerebral veins and dural sinuses thrombosis which results in a distinct clinical condition that involves: chemosis, conjunctival edema, proptosis and painful ophthalmoplegia [8-12]. Frequently, the symptoms start with the involvement of an eye, however, within a few days the other eye tends to be affected via intracavernous sinuses. It was not the case of our patient. There are some major symptoms like headache and high temperature who may occur before the specified syndrome. The close connection between the cavernous sinus and the dura causes meningeal irritation $[11,12]$.

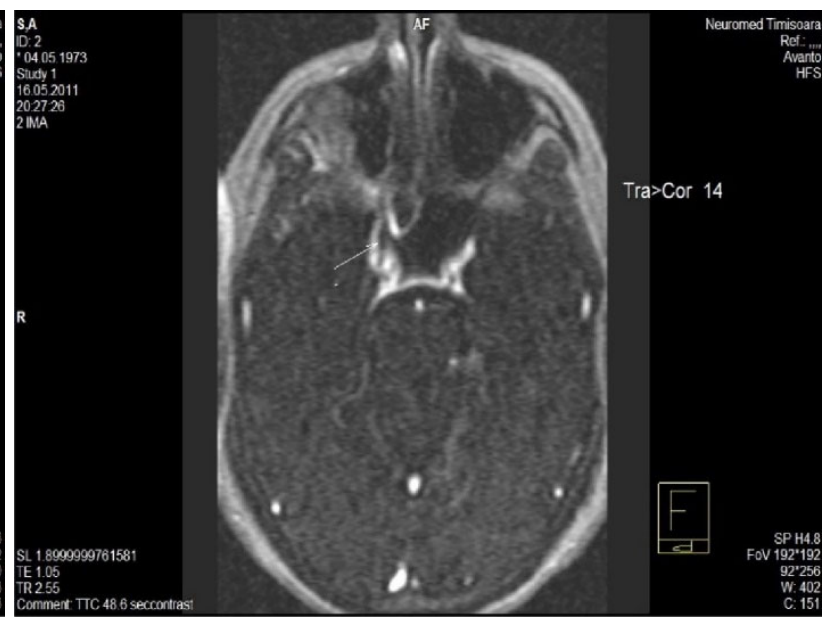

Figure 4 - CE-MRA, venous time - MRP reconstruction in axial plane: lacunar image in right cavernous sinus (arrow). CE-MRA: Contrast enhanced-magnetic resonance angiography; MRP: Median root prior.

According to Southwick et al. (1986), in addition to the clinical signs mentioned above, there can be a large spectrum of other symptoms like cranial nerve palsies, diplopia, even decreased visual acuity, seizures or focal neurological signs like motor deficits, which make the diagnosis of CST challenging [1]. Seizures and motor dysfunction can occur if the occlusion spreads to other sinuses and cortical veins [8].

As we mentioned before, in most of the cases, the etiology is clear; the septic form is the most common, but in between $4.8-12.5 \%$ of cases, the cause is still unknown [1].

Aseptic CST may be caused by head injuries, surgery on intracranial or facial structures, thrombosis of dural arterio-venous fistulas, and prothrombotic states. This condition manifests itself in a more passive manner, with an isolated abducens nerve palsy and minor chemosis and proptosis [8].

In our case, we started to investigate the prothrombotic factors [protein $\mathrm{C}$ and $\mathrm{S}$ deficiency, Factor V Leiden deficiency, raised Factor VIII, Factor II - the prothrombin variant $(P T 20210 A)$, and the homozygosity for methylenetetrahydrofolate reductase (MTHFR) C677T)], as well as markers for vasculitis and autoimmune disorders, but all the results were negative except for the prothrombin G20210A mutation (PT20210A).

$P T 20210 A$ represents the most significant cerebral venous thrombosis (CVT)-regulated hereditary thrombophilic risk factor (it produces a 10 -fold augmentation in the cerebral thrombosis risk) producing an elevation of the plasmatic Factor II level [8-12].

We performed extracranial and transcranial Doppler ultrasonography and transthoracic echocardiography (TTE), both without significant changes. We tested, as well, other infectious causes (HIV, hepatitis B virus and syphilis) and all were negative.

About $85 \%$ of patients with cerebral venous or dural sinus thrombosis (CVST) had at least one contributing factor, according to most reports $[10,13]$. As well as lateral sinus thrombosis (LST), CST may be a complication of otitis media or mastoiditis, which we observe in our 
case. Therefore, those local infections (ear) should be systematically examined by an ENT specialist because of their risk to develop neurological manifestation [13]. Also, those otological infections may be correlated with the potential clinical significance of petrosquamosal sinus (PSS), during otological surgical procedures, as an alternate venous draining route for the posterior fossa, or on its implications in the dissemination of septic thrombosis, but this cause is more often associated with LST, but should be considered especially if the inflammation and bone erosion are noted, as was the case of our patient [14]. Staphylococcus, Streptococcus, and Pneumococcus are the most common bacteria linked to septic CSTs [8-12].

The diagnosis of CVT is based on neuroimaging. In patients who present with new-onset neurological symptoms, such as headache, vomiting, mental alteration, or focal neurological symptoms, CT is typically the first investigation done $[10,15]$. Patients with CST are showing numerous abnormal filling defects with extension and irregularities of their cavernous sinus contours, increased duration and expanded orbital veins after post-contrast CT angiography (CTA) [9, 12].

MRI combined with MRA-venography (MRAV) are now the most sensitive approaches for diagnosis confirmation of CVST, by demonstrating the alteration of signal intensity in dural sinuses on MRI, combined with absence of flow on MRAV [1, 8, 16-18]. On T1- and T2-weighted MR frames, the signal amplitude of the thrombus differs, indicating the thrombus's age [8, 10].

In conclusion, CTA and MRAV can demonstrate dilation of the cavernous sinus, enhancement, and convexity of the lateral wall in coronal views, heterogeneous and asymmetric filling defects following contrast administration, and thrombosis in the superior ophthalmic vein or veins and tributaries leading to the cavernous sinus. Other data are narrowing of the ipsilateral intracranial internal carotid artery, and enhancement of the arterial wall. Ischemic strokes or cerebral hemorrhages may be noted [19-23].

Based on all these facts and the result of blood culture, we considered this was an important septic condition and we continued the treatment that we empirically started at the admission. But our patient presented an episode of pulmonary decompensation, due to a lobar pneumonia, being treated in ICU with another antibiotic with a much wider spectrum, to which she responded well.

The antibiotic or antifungal used was determined by the organism isolated from blood cultures. The commonest empirically used antibiotics were the third generation cephalosporins, Vancomycin and macrolides. The choices are depending somewhat on local antibiotic guidelines and availability. In most of the cases, antibiotics were modified once there was an organism isolated on cultures [24].

Most of the studies did not mention the duration of the treatment with antibiotics but reported that if affection of other organs was suspected (cardiac valves, lungs, or long bones) or an immunocompromised host, than the antibiotics were used for a prolonged course [24]. In our patient, we use cephalosporines for four days and large spectrum Penicillin in association with aminoglycosides for another 10 days.
Considering the antithrombotic treatment, most of the studies consider that the treatment with heparin is safe, even if a hemorrhagic lesion is present on CT or MRI. The aim of this treatment is to reopen an occluded sinus or vein to avoid the thrombus or thrombosis from spreading to other areas of the body [8-10, 25]. Heparin therapy reduces mortality by $14 \%$ and death or dependence by $15 \%$, with proportional risk reductions of $70 \%$ and $56 \%$, respectively, according to a meta-analysis $[8,9,26]$. More than $80 \%$ of patients in the International Study on Cerebral Vein and Dural Sinus Thrombosis (ISCVT) cohort were treated with anticoagulants, showing that anticoagulation is effective in the acute process of CVST [10].

Treatment with heparin is recommended by all guidelines, at patients with acute CVST. Anticoagulation was used as low-molecular-weight heparin (LMWH) (180 U/kg/24 hours delivered through two subcutaneous injections daily) or dose-adjusted iv unfractionated heparin, with the monitorization of activated partial thromboplastin time (aPTT) and continued after discharge with oral anticoagulants [10, 16, 26, 27]. In our case, we started the treatment with LMWH (Enoxaparin), and we switched on oral anticoagulant with Acenocoumarol, which must be continued for at least three months.

Enoxaparin has been shown to decrease death rates and is linked to a higher rate of rehabilitation [27-29].

Corticosteroids are often given but without clear efficacy. They can reduce the inflammation and vasogenic edema surrounding cranial nerves. In ISCVT, steroid usage was documented in $24 \%$ of cerebral thrombosis cases, with no indication of progress $[10,19]$. We did not use corticosteroids in our patient.

The cavernous sinuses may not need surgery, although certain patients may need a sphenoidotomy, abscess drainage or orbital decompression [19]. We did not use them in our case.

Recanalization of the thrombosed cerebral vein and sinus develops in $40-90 \%$ of CVT patients, with most cases occurring during the first four months [8, 10, 16, 17]. As contrast to other systems, the deep venous system and the cavernous sinus have a greater rate of recanalization. But the recanalization of the occluded sinus does not influence the outcome after CVST [8, 10, 17]. It is recommended for the patient to undergo MRI/MR venography three to six months after CVST to document the extent of recanalization [15].

A lot of other diagnosis which can mimic the clinical manifestation of CVST must be excluded; this includes orbital cellulitis, orbital apex syndrome or carotidcavernous fistula [30].

The prognosis of CST has improved considerably in the era of antibiotics, with a mortality between $8 \%$ and $13 \%$ [19]. But a lot of patients might have sequelae including third or sixth nerve palsy, blindness, intracranial hypertension, vasospasm, brain abscess, meningitis, which can conduct to a permanent disability [19, 31-35]. Fortunately, it was not the case of our patient which has made a full recovery.

\section{ㅁ Conclusions}

CST is diagnosed based on a high initial clinical suspicion, with MRI combined with MRA being the 
"gold standard" tool for detecting the cavernous sinus filling defects, as was in our study. As well, blood flow in the cavernous sinus improved after anticoagulation, if good response to the large antibiotic spectrum, which is consistent with the literature. Early detection of CST, which may include a wide range of signs such as fever, headache, and eye abnormalities, such as periorbital swelling and ophthalmoparesis, is important for a positive result. Despite advanced therapy with antibiotics and anticoagulants, most patients developed long-term complications, such as vision impairment, diplopia, and cerebral infarction.

\section{Conflict of interests}

The authors state that there is no conflict of interests.

\section{References}

[1] Southwick FS, Richardson EP Jr, Swartz MN. Septic thrombosis of the dural venous sinuses. Medicine (Baltimore), 1986, 65(2):82-106. https://doi.org/10.1097/00005792-198603000 -00002 PMID: 3512953

[2] DiNubile MJ. Septic thrombosis of the cavernous sinuses. Arch Neurol, 1988, 45(5):567-572. https://doi.org/10.1001/ archneur.1988.00520290103022 PMID: 3282499

[3] Lai PF, Cusimano MD. The spectrum of cavernous sinus and orbital venous thrombosis: a case and a review. Skull Base Surg, 1996, 6(1):53-59. https://doi.org/10.1055/s-2008 -1058913 PMID: 17170953 PMCID: PMC1656512

[4] Pavlovich P, Looi A, Rootman J. Septic thrombosis of the cavernous sinus: two different mechanisms. Orbit, 2006, 25(1) 39-43. https://doi.org/10.1080/01676830500506077 PMID: 16527775

[5] Ferri FF. Ferri's clinical advisor 2016: 5 books in 1. $1^{\text {st }}$ edition, Elsevier Health Sciences, Philadelphia, 2015, 1133.

[6] Zhang J, Stringer MD. Ophthalmic and facial veins are not valveless. Clin Exp Ophthalmol, 2010, 38(5):502-510. https:// doi.org/10.1111/j.1442-9071.2010.02325.x PMID: 20491800

[7] Sharouny H, Narayanan P. Endoscopic marsupialisation of the lateral frontal sinus mucocele with orbital extension: a case report. Iran Red Crescent Med J, 2015, 17(1):e17104. https://doi.org/10.5812/ircmj.17104 PMID: 25763256 PMCID: PMC4341355

[8] Jianu DC, Jianu SN, Munteanu G, Dan TF, Bârsan C. Chapter 3: Cerebral vein and dural sinus thrombosis. In Sanchetee $\mathrm{P}$ (ed). Ischemic stroke of brain. IntechOpen, London, UK, 2018, 45-76. https://doi.org/10.5772/intechopen. 76918

[9] Bousser MG, Barnett HJM. Chapter 12: Cerebral venous thrombosis. In: Mohr JP, Choi DW, Grotta JC, Weir B, Wolf PA (eds). Stroke: pathophysiology, diagnosis, and management. $4^{\text {th }}$ edition, Churchill Livingstone, Philadelphia, PA, USA, 2004 301-325. https://www.elsevier.com/books/stroke/978044306 6009

[10] Ferro JM, Canhão P. Chapter 45: Cerebral venous thrombosis. In: Grotta JC, Albers GW, Broderick JP, Kasner SE, Lo EH, Mendelow AD, Sacco RL, Wong LKS (eds). Stroke: pathophysiology, diagnosis, and management. $6^{\text {th }}$ edition, Elsevier, Amsterdam, 2016, 716-730. https://www.elsevier.com/books/ stroke/grotta/978-0-323-29544-4

[11] Roach ES, Bettermann K, Biller J. Chapter 20: Sinovenous occlusion. In: Roach ES, Bettermann K, Biller J (eds). Toole's cerebrovascular disorders. $6^{\text {th }}$ edition, Cambridge University Press, New York, USA, 2010, 283-292. https://assets.cam bridge.org/97805218/66224/frontmatter/9780521866224_fron tmatter.pdf

[12] Caplan LR. Chapter 16: Cerebral venous thrombosis. In: Caplan LR (ed). Caplan's stroke: a clinical approach. $4^{\text {th }}$ edition, Elsevier-Saunders, Philadelphia, PA, USA, 2010, 554-578. https://www.elsevier.com/books/T/A/9781416047216

[13] Brismar G, Brismar J. Aseptic thrombosis of orbital veins and cavernous sinus. Clinical symptomatology. Acta Ophthalmol (Copenh), 1977, 55(1):9-22. https://doi.org/10.1111/j.17553768.1977.tb06091.x PMID: 576549
[14] Jianu DC, Jianu SN, Motoc AGM, Poenaru M, Petrica L, Vlad A, Ursoniu S, Gogu AE, Dan TF. Diagnosis and management of a young woman with acute isolated lateral sinus thrombosis. Rom J Morphol Embryol, 2017, 58(4):1515-1518. PMID: 29556650

[15] Jianu DC, Jianu SN, Dan TF, Motoc AG, Poenaru M. Pulsatile tinnitus caused by a dilated left petrosquamosal sinus. Rom J Morphol Embryol, 2016, 57(1):319-322. PMID: 27151729

[16] Einhäupl K, Stam J, Bousser MG, De Bruijn SF, Ferro JM, Martinelli I, Masuhr F; European Federation of Neurological Societies. EFNS Guideline on the treatment of cerebral venous and sinus thrombosis in adult patients. Eur J Neurol, 2010, 17(10):1229-1235. https://doi.org/10.1111/j.1468-1331.2010. 03011.x PMID: 20402748

[17] Ferro JM, Canhão P. Chapter 10: Cerebral venous sinus thrombosis. In: Biller J, Ferro JM (eds). Evidence-based management of stroke. $1^{\text {st }}$ edition, Gutenberg Press Ltd., Tarxien, Malta, 2011, 205-220. https://2lib.org/book/218949 $9 / 1$ b85f9?id=2189499\&secret=1b85f9\&dsource=recommend

[18] Piazza G. Cerebral venous thrombosis. Circulation, 2012, 125(13):1704-1709. https://doi.org/10.1161/CIRCULATION AHA.111.067835 PMID: 22474313

[19] Qu H, Yang M. Early imaging characteristics of 62 cases of cerebral venous sinus thrombosis. Exp Ther Med, 2013, 5(1):233-236. https://doi.org/10.3892/etm.2012.796 PMID: 23251274 PMCID: PMC3523955

[20] Plewa MC, Tadi P, Gupta M. Cavernous sinus thrombosis. In: Stat Pearls [Internet]. Stat Pearls Publishing, Treasure Island, FL, USA, 2020. https://www.ncbi.nlm.nih.gov/books/ NBK448177

[21] Branson SV, McClintic E, Yeatts RP. Septic cavernous sinus thrombosis associated with orbital cellulitis: a report of 6 cases and review of literature. Ophthalmic Plast Reconstr Surg, 2019, 35(3):272-280. https://doi.org/10.1097/IOP.00000000 00001231 PMID: 30320718

[22] Deliran SS, Sondag L, Leijten QH, Tuladhar AM, Meijer FJA. [Headache: consider cavernous sinus thrombophlebitis]. Ned Tijdschr Geneeskd, 2018, 162:D2907. PMID: 30212024

[23] Fujikawa T, Sogabe Y. Septic cavernous sinus thrombosis: potentially fatal conjunctival hyperemia. Intensive Care Med, 2019, 45(5):692-693. https://doi.org/10.1007/s00134-018-5 322-6 PMID: 30062575

[24] van der Poel NA, de Witt KD, van den Berg R, de Win MM, Mourits MP. Impact of superior ophthalmic vein thrombosis: a case series and literature review. Orbit, 2019, 38(3):226232. https://doi.org/10.1080/01676830.2018.1497068 PMID: 30040506

[25] Weerasinghe D, Lueck CJ. Septic cavernous sinus thrombosis: case report and review of the literature. Neuroophthalmology, 2016, 40(6):263-276. https://doi.org/10.1080/01658107.2016. 1230138 PMID: 27928417 PMCID: PMC5120738

[26] Bousser MG, Ferro JM. Cerebral venous thrombosis: an update. Lancet Neurol, 2007, 6(2):162-170. https://doi.org/ 10.1016/S1474-4422(07)70029-7 PMID: 17239803

[27] de Bruijn SFTM, Stam J; Cerebral Venous Sinus Thrombosis Study Group. Randomized placebo-controlled trial of anticoagulant treatment with low-molecular-weight heparin for cerebral sinus thrombosis. Stroke, 1999, 30(3):484-488. https://doi.org/10.1161/01.str.30.3.484 PMID: 10066840

[28] Ferro JM, Bousser MG, Canhão P, Coutinho JM, Crassard I, Dentali F, di Minno M, Maino A, Martinelli I, Masuhr F, Aguiar de Sousa D, Stam J; European Stroke Organization. European Stroke Organization Guideline for the diagnosis and treatment of cerebral venous thrombosis - endorsed by the European Academy of Neurology. Eur J Neurol, 2017, 24(10):1203-1213. https://doi.org/10.1111/ene.13381 PMID: 28833980

[29] Stam J, de Bruijn SFTM, deVeber G. Anticoagulation for cerebral sinus thrombosis. Cochrane Database Syst Rev, 2002, (4):CD002005. Update in: Cochrane Database Syst Rev, 2011, (8):CD002005. https://doi.org/10.1002/1465185 8.CD002005 PMID: 12519565

[30] Levine SR, Twyman RE, Gilman S. The role of anticoagulation in cavernous sinus thrombosis. Neurology, 1988, 38(4):517522. https://doi.org/10.1212/wnl.38.4.517 PMID: 3281056

[31] Petrica L, Petrica M, Munteanu M, Vlad A, Bob F, Gluhovschi C, Gluhovschi G, Jianu C, Schiller A, Velciov S, Trandafirescu V, Bozdog G. Cerebral microangiopathy in 
patients with non-insulin-dependent diabetes mellitus. Ann Acad Med Singap, 2007, 36(4):259-266. PMID: 17483855

[32] Vlad A, Vlad M, Petrica L, Ursoniu S, Gadalean F, Popescu R, Vlad D, Dumitrascu V, Gluhovschi G, Gluhovschi C, Velciov S, Bob F, Matusz P, Secara A, Simulescu A, Jianu DC. Therapy with atorvastatin versus rosuvastatin reduces urinary podocytes, podocyte-associated molecules, and proximal tubule dysfunction biomarkers in patients with type 2 diabetes mellitus: a pilot study. Ren Fail, 2017, 39(1):112-119. https://doi.org/10.10 80/0886022X.2016.1254657 PMID: 27841047 PMCID: PMC 6014491

[33] Frank GS, Smith JM, Davies BW, Mirsky DM, Hink EM, Durairaj VD. Ophthalmic manifestations and outcomes after cavernous sinus thrombosis in children. J AAPOS, 2015,
19(4):358-362. https://doi.org/10.1016/j.jaapos.2015.06.001 PMID: 26239205

[34] Petrica L, Vlad A, Gluhovschi G, Gadalean F, Dumitrascu V, Vlad D, Popescu R, Velciov S, Gluhovschi C, Bob F, Ursoniu S, Petrica M, Jianu DC. Glycated peptides are associated with the variability of endothelial dysfunction in the cerebral vessels and the kidney in type 2 diabetes mellitus patients: a crosssectional study. J Diabetes Complications, 2015, 29(2):230237. https://doi.org/10.1016/j.jdiacomp.2014.11.014 PMID: 25511877

[35] Laupland KB. Vascular and parameningeal infections of the head and neck. Infect Dis Clin North Am, 2007, 21(2):577-590, viii. https://doi.org/10.1016/j.idc.2007.03.011 PMID: 17561084

\section{Corresponding authors}

Andrei Gheorghe Marius Motoc, Professor, MD, PhD, Specialist in Obstetrics-Gynecology, Department of Anatomy and Embryology, Victor Babeş University of Medicine and Pharmacy, 2 Eftimie Murgu Square, 300041 Timişoara, Romania; Phone/Fax +40256-220 482, Mobile +40722-277 806, e-mail: amotoc@umft.ro

Georgiana Munteanu, MD, Specialist in Neurology, First Department of Neurology, Pius Brânzeu Emergency County Hospital, IX Floor, 156 losif Bulbuca Street, 300736 Timişoara, Romania; Mobile +40746-151 426, e-mail: isfan_georgiana@yahoo.com

Received: January 27, 2021

Accepted: May 24, 2021 